\title{
5-Hydroxytryptamine and cholera secretion: a histochemical and physiological study in cats
}

\author{
O NILSSON, J CASSUTO, P-A LARSSON, M JODAL, P LIDBERG, H AHLMAN, \\ A DAHLSTRÖM, AND O LUNDGREN
}

From the Institute of Neurobiology and Department of Physiology, University of Göteborg, and Department of Surgery III, Sahlgren's Hospital, Göteborg, Sweden

SUMmARY The effect of cholera toxin on the content of 5-hydroxytryptamine (5-HT) in the enterochromaffin cells of the cat small intestine was estimated by cytofluorimetry of individual enterochromaffin cells at varying times after exposing the intestinal mucosa to the toxin. The observed changes in 5-HT levels in the enterochromaffin cells were correlated with the simultaneously measured rate of net fluid transport across the intestinal epithelium. Intestinal segments exposed to cholera toxin showed a statistically significant decrease in 5-HT levels of enterochromaffin cells compared with segments exposed to heat-inactivated cholera toxin. A good correlation $(r=0.73)$ was found between relative 5-HT fluorescence in enterochromaffin cells and net fluid transport across the intestinal epithelium. Thus, a diminished 5-HT content was associated with a decreased rate of fluid absorption or an increased rate of secretion. A hypothesis is presented for explaining the possible role of the enterochromaffin cells in the pathophysiology of cholera secretion.

During the last decade it has become increasingly clear that the hormonal and nervous control of gastrointestinal function is very complex indeed. The number of hormones and hormone 'candidates' ${ }^{\prime}$ has increased dramatically. The enteric nervous system, previously believed to consist only of adrenergic and cholinergic neurons, has been shown to contain several types of peptidergic nerve cells, many of which appear to store one of the classical transmitters in addition to the peptide (for a recent review, see reference -2 ). It may be assumed that gastrointestinal homones and enteric nerves not only play a physiological role, but are also of importance in the pathophysiology of different diseases. Candidate hormones have been inferred in discussions of secretory diarrhoeas - for example, the Verner-Morrison syndrome. It is usually assumed, however, that neither nerves nor hormones are of any importance in explaining the severe fluid loss from the gut seen in cholera.

Nevertheless, we have recently presented experimental evidence for an involvement of the enteric

Address for correspondence: Ove Lundgren, Department of Physiology, P.O.B. 33 031, S-400 33 Göteborg. Sweden.

Received for publication 27 August 1982 nervous system in the pathophysiology of choleraic secretion. ${ }^{3}$ According to our hypothesis, the cholera toxin may trigger the release of 5-hydroxytryptamine (5-HT) from the enterochromaffin cells (Fig. 1). The released 5-HT may, in turn, activate dendrites often observed adjacent to the enterochromaffin cells. ${ }^{4-6}$ The dendrites may be part of the afferent link in the proposed enteric nervous reflex(es), the net effect of which is secretion of fluid from the intestinal epithelium. According to Cassuto et $\mathrm{al}^{3}$ about $60 \%$ of the effect of the cholera toxin on intestinal fluid transport could be ascribed to nervous mechanism(s). The experimental evidence for this hypothesis includes, inter alia, the demonstration that tetrodotoxin, blocking action potentials, and hexamethonium, a cholinergic ganglionic receptor blocker, abolished net fluid secretion in rat and cat intestinal segments which were exposed to cholera toxin (for a further discussion of the hypothesis, see Discussion).

One crucial point in the hypothesis outlined above is the demonstration that cholera toxin triggers a release of 5-HT from the enterochromaffin cells. In this study we have obtained direct evidence at the cellular level for such release of 5-HT from enterochromaffin cells after cholera toxin exposure. The observed decrease of 5-HT in these cells was 


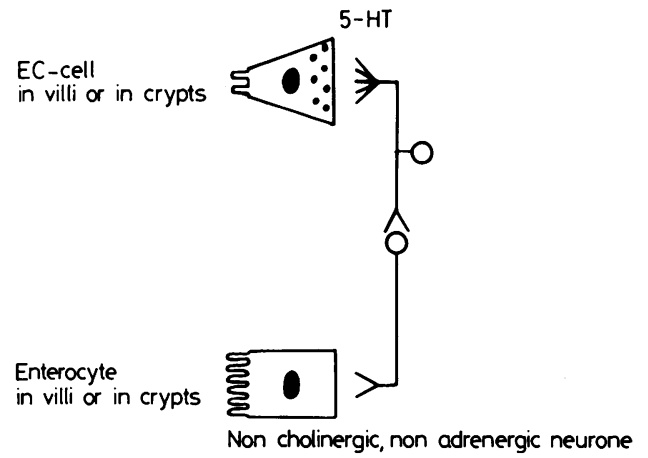

Fig. 1 Schematic illustration of the hypothesis inferring the involvement of the enterochromaffin (EC) cells and the enteric nervous system in the pathophysiology of choleraic secretion. Cholera toxin triggers the release of 5 hydroxytryptamine (5-HT) from the enterochromaffin cells. The released 5-HT activates, in turn, dendrites adjacent to the enterochromaffin cells. The dendrites are part of the afferent link in the proposed enteric nervous reflex(es), also involving cholinergic ganglionic receptors. The efferent link is constituted by non-cholinergic, non-adrenergic neurons which evoke intestinal secretion.

correlated with the simultaneously measured net fluid transport across the feline small intestinal epithelium.

A preliminary report of this study has been published. $^{7}$

\section{Methods}

\section{OPERATIVE PROCEDURES}

The experiments were performed on cats $(2.5-4 \mathrm{~kg})$ anaesthetised with chloralose $(50 \mathrm{mg} / \mathrm{kg}$ bw intravenously) after induction with ether. The cats were fasted for 24 hours but had free access to water. They exhibited no obvious signs of gastrointestinal disease.

The operative procedures were similar to those described by Jodal et al. ${ }^{8}$ After tracheotomy, the abdomen was opened by a midline incision, and three intestinal segments with intact vascular supply were isolated: one segment, about $25 \mathrm{~cm}$ long, for fluorescence microscopy, a second part, about $10 \mathrm{~cm}$ in length, for studies of net water transport, and a third segment, $5-10 \mathrm{~cm}$ long, was used as a control segment. The remainder of the small intestine, the colon, the spleen, and the great omentum were extirpated. The left adrenal gland was denervated and the right one excluded from the circulation by ligatures, to minimise changes in the adrenal outflow of catecholamines while maintaining the necessary release of adrenal steroids.
After heparinising the animal $(3-5 \mathrm{mg} / \mathrm{kg}$ bw intravenously), blood pressure was measured by a pressure transducer (Statham P23AC) in the femoral artery. For venous outflow recordings the superior mesenteric vein, draining the intestinal segment and its lymph nodes, was cannulated and connected to a drop recorder unit, operating an ordinate writer. Cholinergic influences were eliminated by administration of atropine $(1 \mathrm{mg} / \mathrm{kg}$ bw intravenously).

RECORDING OF INTESTINAL NET FLUID TRANSPORT In all experiments the rate of intestinal net fluid transport was followed continuously with the technique described by Jodal et al. ${ }^{8}$ Briefly, the lumen of the short intestinal segment was perfused at a constant rate $(1 \mathrm{ml} / \mathrm{min})$ with a solution of known composition (see below) in a closed perfusion system with a reservoir large enough to prevent recirculation. Changes in the circulating volume were continuously recorded by a volume transducer coupled to a Grass polygraph and connected to the perfusion system via a T-tube. When no intestinal motility occurred, as in these experiments using atropine-pretreated animals, the changes in the perfusion volume reflected net water transport across the intestinal epithelium.

\section{CYTOFLUORIMETIC PROCEDURE}

At varying times (in most experiments 0 , one, three, and five hours) after the onset of the experiments, small biopsies $(3 \times 5 \times 3 \mathrm{~mm})$ of the gut wall were dissected with great care, with at least $1 \mathrm{~cm}$ of free intact gut between the various biopsy sites. The biopsies were placed on coded paper pieces and frozen immediately in liquid propane, cooled by liquid nitrogen. After freeze drying, the specimens were reacted with paraformaldehyde gas at $80^{\circ} \mathrm{C}$ for one hour. During the treatment with formaldehyde gas the tissue catecholamines - for example, noradrenaline in adrenergic nerves - and 5- HT - in enterochromaffin cells - are converted to strongly fluorescent (green and yellow, respectively) substances in situ. Using the fluorescence microscope the amines can be localised at the cellular level and quantified, as the fluorescence intensity of the formed compounds is proportional to the amine concentrations in biological samples (for detailed description and discussion see, for example, references 9 and 10). After embedding the reacted specimens in paraffin wax in vacuo, thin 10 $\mu \mathrm{m}$ sections were cut, mounted in Entellane ${ }^{R}$ Xylene, and examined in a Leitz MPV II cytofluorimeter, a fluorescence microscope equipped with devices for registering fluorescence intensity in single cells. The 5-HT-induced fluorescence of 20 
randomly selected enterochromaffin cells situated in the crypts and on the villi (separately), was measured in each sample, as described previously. ${ }^{11}$ The intensity of the 5-HT-induced fluorescence in biopsies from the first experimental segment was correlated to the mean 5-HT-fluorescence in biopsies from a 0 hour control segment, removed before the onset of the cholera exposure (see below), and normalised to this control value. This procedure was followed for each individual experiment.

\section{SOLUTIONS}

The lumen of the intestinal segments was perfused with a modified Krebs-Henseleit solution, containing (mmol/l): $\mathrm{Na} 122 . \mathrm{KCl} 4 \cdot 7, \mathrm{KH}_{2} \mathrm{PO}_{4} 1 \cdot 2$, $\mathrm{MgCl}_{2} \times 6 \mathrm{H}_{2} \mathrm{O} 1 \cdot 2, \mathrm{CaCl}_{2} 2 \cdot 5, \mathrm{NaHCO}_{3} 25$, mannitol 30. The osmolality of the solution ranged between 305 and $315 \mathrm{mOsm} / \mathrm{kg} \mathrm{H}_{2} \mathrm{O}$.

In order to maintain a normal acid-base balance of the animal, a bicarbonate-glucose solution (100 mmol $\mathrm{NaHCO}_{3}$ per 1 of a $550 \mathrm{M}$ glucose solution) was infused intravenously at a rate of $0.1 \mathrm{ml} / \mathrm{min}$ througout the experiment. ${ }^{12}$

\section{EXPERIMENTAL PROCEDURES}

After completing the operative procedures the animals were allowed to 'rest' for 30-40 minutes before control measurements of the different parameters were made. A $5 \mathrm{~cm}$ segment was isolated from the long intestinal loop and extirpated. Biopsies ( 0 hour control) were taken from this segment for cytofluorimetry, and immediately frozen as described above.

In order to produce choleraic secretion, $300-400$ $\mathrm{mg}$ per $15 \mathrm{~cm}$ of intestine of a crude cholera toxin (freeze-dried culture filtrate), dissolved in $5-10 \mathrm{ml}$ physiological saline, was introduced into the lumen of the first two of the isolated intestinal segments in seven cats. ${ }^{*}$ The third segment served as a control. After 30 minutes of cholera toxin exposure, the intestinal lumen was carefully rinsed with $50 \mathrm{ml}$ saline at $37^{\circ} \mathrm{C}$. During the following four-five hours all cats developed intestinal secretion, although in one experiment the secretion was only transient. Arterial blood pressure, intestinal blood flow, and intestinal net fluid transport were continuously followed. The biopsies for fluorescence microscopy were removed one-five hours after the onset of incubation with cholera toxin. Biopsies from the control segment were removed at the end of the experiment (at five hours).

In four control experiments the cholera toxin was inactivated by heating to $56^{\circ} \mathrm{C}$ for $45-60$ minutes

* The toxin was kindly supplied by Professor Jan Holmgren. Department of Medical Microbiology. University of Göteborg. before instillation into the lumen. The experiments were then performed as described above.

STATISTICAL ANALYSIS

For statistical analysis of the results the Wilcoxon's tests for unpaired or paired observations, or the Sign test $^{13}$ were used. Differences with $p \leqslant 0.05$ were considered significant.

\section{Results}

In specimens from control gut segments numerous enterochromaffin cells with brightly yellow fluorescence were observed in crypts and villi (Fig. 2 a). This 5-HT-induced fluorescence in the cytoplasm had a granular appearance, while the nucleus was dark. Green fluorescent varicose adrenergic nerve terminals (containing the noradrenaline fluorophore, produced by the formaldehyde reaction) were present in the submucous layer and in the connective tissue stroma between the crypts and in the villi. One to five hours after the application of cholera toxin the fluorescence intensity of the enterochromaffin cells was markedly decreased in both crypts and villi (Fig. 2 b).

In some cats the maximal decrease of fluorescence was already apparent one hour after exposing the intestinal mucosa to the toxin, while in others the maximal decrease occurred later. An experiment of the latter type is illustrated in the right panel of Fig. 3 . In the left panel an experiment with the heatinactivated cholera toxin is shown. No significant 5-HT decrease could be measured, and no secretory response appeared. In one experiment, illustrated in Fig. 4, a transient effect of the cholera toxin on net fluid transport was noted. A similar parallel effect was observed with regard to the 5-HT-fluorescence.

Results from the control segment and from the five hour observations of cholera exposed segments with a sustained secretion are shown in the Table (cf. Fig. 4). A statistically significant $(p<0 \cdot 05)$ decrease of 5-HT fluorescence in the enterochromaffin cells of the intestinal segments after exposure to the active cholera toxin was observed. Fig. 5 shows the relative 5-HT-fluorescence in enterochromaffin cells plotted versus net fluid transport across the intestinal epithelium, including all the observations of the present study.

A control segment (five hour control), not exposed to the toxin but left in the animal for the entire experimental period, was studied with fluorescence microscopy in five of seven cholera experiments, including the one illustrated in Fig. 4. In these control segments the relative fluorescence in the enterochromaffin cells was lower than in 0 hour control specimens - a small decrease (about 


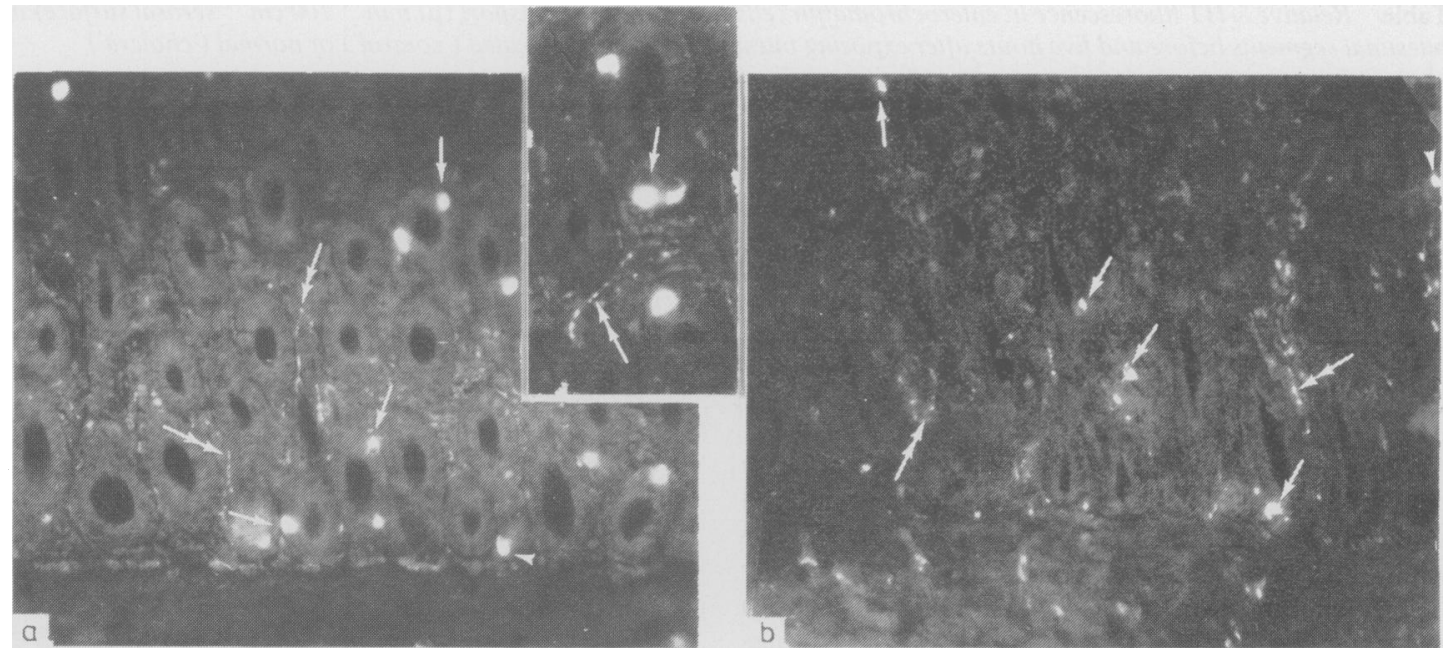

Fig. 2 Fluorescence micrographs from small intestinal crypts (submucosa at bottom) from one cat before (a) and after (b) three hours' exposure to cholera toxin. Yellow fluorescent 5-HT containing enterochromaffin cells (single arrows) in the intestinal epithelium and mast cells (arrow heads) in interstitial tissue can be seen. Crypts are often surrounded by fine varicose green fluorescent adrengeric nerve terminals (double arrows-see inset). Note the marked decrease in fluorescence intensity of the enterochromaffin cells after cholera toxin treatment as well as the slight diffusion of the green fluorophore from adrenergic nerve terminals. Each enterochromaffin cell 20-25 $\mu \mathrm{m}$ in length. $\times 120$ (original magnification).

$20 \%$ ), often observed in animals during prolonged experiments of any kind. The five hour control value, however, was significantly higher than that measured in the choleraic secreting intestinal segments $(p<0.05)$. The relative 5-HT fluorescence in the five hour control segments was $0.79 \pm 0.06$ (mean $\pm \mathrm{SE}, \mathrm{n}=5$ ), and in the corresponding five hour choleraic segments $0 \cdot 57 \pm 0 \cdot 07(\mathrm{p}<0 \cdot 05)$.

\section{Discussion}

The observed decrease in 5-HT fluorescence intensity in enterochromaffin cells, likely to reflect a true decrease in 5-HT, ${ }^{9}$ after cholera toxin exposure may be due to several factors: (1) an increased release over basal of 5-HT granules from the enterochromaffin cells, (2) a decreased formation of 5-HT-storing granules, while a basal release is maintained, (3) a normal production of granules containing less 5-HT than normal, with basal release, (4) a combination of the possibilities 1-3. Alternative (3) is not likely, as the distribution of 5-HT fluorescence after cholera toxin incubation in most cells was very irregular and patchy, unlike the
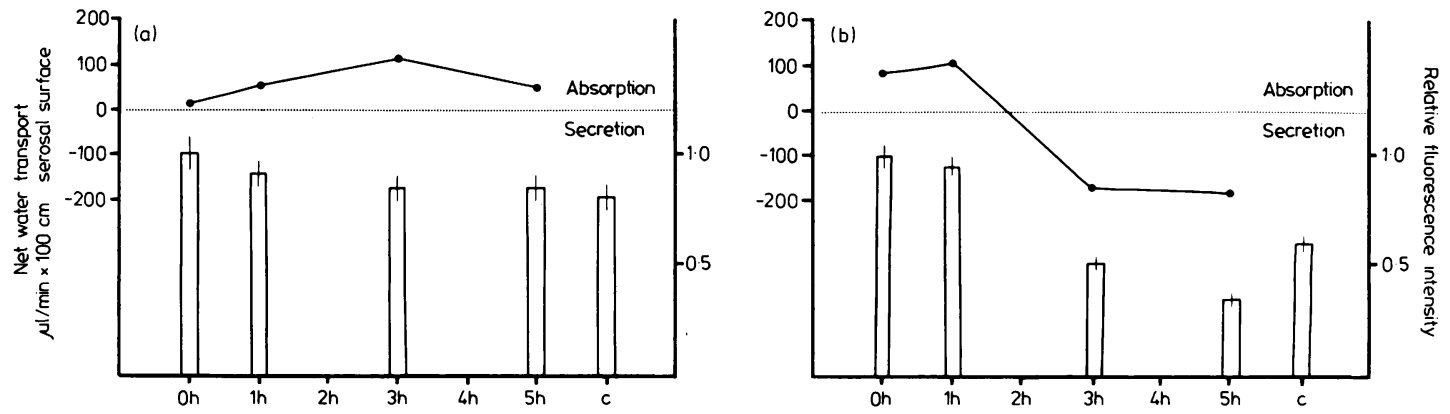

Fig. 3 Effect of heat inactivated cholera toxin (left panel) and cholera toxin (right panel) on 5-HT contents in enterochromaffin cells (columns) and net fluid transport in the intestine ( $\bullet$ ) in representative experiments. Bars on columns denote $S E$ of relative fluorescence in 20 studied cells. Note the close parallelism between 5-HT fluorescence and fluid transport. 
Table Relative 5-HT fluorescence in enterochromaffin cells and net water transport ( $\mu l \mathrm{~min}^{-1} 100 \mathrm{~cm}^{-2}$ serosal surface) in intestinal segments before and five hours after exposing intestinal segments to heated ('control') or normal ('cholera') cholera toxin

\begin{tabular}{|c|c|c|c|c|c|}
\hline & \multicolumn{2}{|l|}{ O hours } & \multicolumn{2}{|l|}{5 hours } & \multirow[b]{2}{*}{$n$} \\
\hline & $\begin{array}{l}\text { Relative } \\
\text { fluorescence }\end{array}$ & $\begin{array}{l}\text { Net fluid } \\
\text { transport }\end{array}$ & $\begin{array}{l}\text { Relative } \\
\text { fluorescence }\end{array}$ & $\begin{array}{l}\text { Net fluid } \\
\text { transport }\end{array}$ & \\
\hline Control & 1.00 & $129 \pm 71$ & $0 \cdot 88 \pm 0 \cdot 06$ & $161 \pm 54$ & 4 \\
\hline Cholera & 1.00 & $137 \pm 63$ & $0 \cdot 64 \pm 0 \cdot 10$ & $-166 \pm 59$ & 6 \\
\hline
\end{tabular}

- denotes net fluid secretion. $n$ : number of observations. Mean $\pm S E$.

picture in control segments. If basal secretion were maintained and the number of granules produced were normal, but with less 5-HT per granule, one would expect to see a normal distribution of weaker 5-HT fluorescence. Osaka et l $^{14}$ reported that an increased percentage of enterochromaffin granules appeared 'swollen' and devoid of their usual osmiophilic contents after cholera exposure, an observation which may suggest that newly produced granules contain less 5-HT than usual. A significant number of granules had made contact with the cell membrane (so called Ohmega position); this observation is considered to reflect an increased granular release. Furthermore, the Golgi complex of these enterochromaffin cells appeared to be enlarged, and there were newly formed granules in and near the Golgi complex, a phenomenon interpreted by Osaka et al as an increased synthesis of storage granules in the enterochromaffin cells. Our observations, together with the report by Osaka et $\mathrm{al}^{14}$ therefore strongly suggest that cholera toxin induces an increased release of 5-HT from the enterochromaffin cells (alternative (1)) together with a compensatory increase in the production of granules from the Golgi complex, but a production of apparently defective granules.

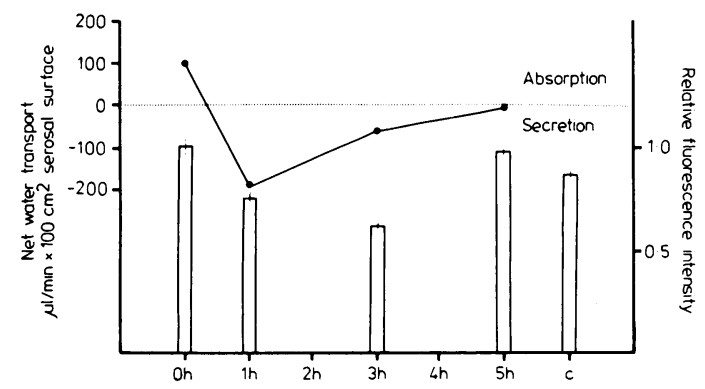

Fig. 4 Transient effect of cholera toxin on net fluid transport in the intestine paralleled by a similar effect on relative 5-HT fluorescence in enterochromaffin cells. For explanation of symbols used, see Fig. 3.
The experiments reported in this study thus suggest that the enterochromaffin cells discharge large parts of their content of 5-HT after exposing the small intestine to cholera toxin. A strikingly good correlation between decrease in intracellular 5-HT contents and net fluid transport (Figs. 3-5) was also demonstrated. Thus, a diminished intracellular 5-HT content, due to a marked release of 5-HT, was associated with a decreased rate of fluid absorption or an increased rate of secretion.

The present observations are in agreement with the hypothesis outlined in the introduction (Fig. 1), implying that the cholera toxin causes the release of 5-HT by adhering to the enterochromaffin cell. One possible mediator of this effect of the toxin may be cyclic AMP, which is increased in all hitherto investigated cell systems exposed to cholera toxin. ${ }^{15}$ The possible effect of an increased concentration of cyclic AMP on the release of 5-HT from the enterochromaffin cell is not known. Other cells belonging to the APUD (amine precursor uptake

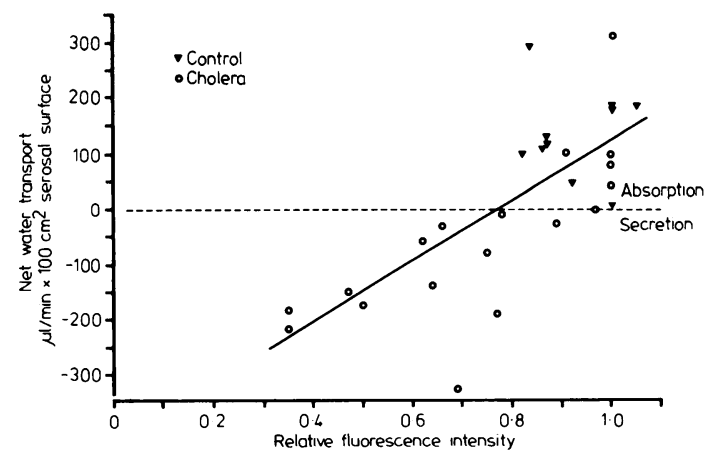

Fig. 5 Relative 5-HT fluorescence in enterochromaffin cells plotted versus net fluid transport across the intestinal epithelium, including all the observations of the present study. Each point represents the average value of 20 measurements of relative intracellular 5-HT content. A good correlation between the two measured variables is apparent, the $r$-value being $0 \cdot 73$. The drawn line $(y=567 x-439)$ was constructed by the method of least squares. 
and decarboxylating) system, ${ }^{16}$ however, have been studied with regard to the effects of cyclic AMP. Parafollicular cells of the thyroid, containing granules storing both 5-HT and calcitonin, release an increased amount of calcitonin upon intravascular administration of cyclic AMP. ${ }^{17}$ It therefore seems possible that an increase of the intracellular concentration of the cyclic nucleotide may in some way be involved in triggering the release of 5-HT from the enterochromaffin cells.

It has been suggested that 5-HT is stored in the enterochromaffin cell together with substance $P$ (mouse, rat, guinea-pig, cat, chicken, duck, ${ }^{18}$ rabbit, $\left.{ }^{18}{ }^{19}\right)$, motilin (dog, pig, baboon, ${ }^{20}$ man, ${ }^{20-22}$ ) or enkephalin $\left(\mathrm{pig}^{23}\right)$. These reports have, however, been challenged by other investigators (motilin: man, monkey; ${ }^{24}$ enkephalin: guinea pig, rat, hamster. ${ }^{25}$ ) If these polypeptides are stored together with 5-HT in the granules it seems likely that they also are discharged after exposing the small intestine to cholera toxin. The released peptides may then exert a paracrine action on adjacent enterocytes and/or a remote endocrine effect. With regard to peptides which may coexist with 5-HT in the enterochromaffin cell, enkephalin is known to inhibit intestinal secretion, ${ }^{26}$ while substance $P$ seems to induce an intestinal electrolyte secretion in vitro. ${ }^{27}$ To our knowledge, no study on motilin and intestinal transport has been reported.

The probable participation of 5-HT in the induction of cholera secretion (cf. Fig. 1) is supported by observations from our laboratory and reported elsewhere. Firstly, by making the rat intestine tachyphylactic against 5-HT, cholera secretion is inhibited ${ }^{28}$ Secondly, methysergide, a 5-HT receptor blocker, also abolished cholera secretion. ${ }^{29}$ It should in this context be pointed out that chlorpromazine, a compound used in the treatment of cholera ${ }^{30}$ is, among, other things, a fairly potent 5 -HT receptor blocker. ${ }^{31}$ Finally, the 5 -HT-induced secretion in normal intestine is blocked by tetrodotoxin and by hexamethonium, ${ }^{3}$ inferring the involvement of nerves in the 5-HTinduced secretion ( $c f$. Fig. 1).

According to the hypothesis schematically illustrated in Fig. 1, the 5-HT released from the enterochromaffin cells may activate dendritic processes lying adjacent to these cells in the crypts and in the villi. Such an anatomical arrangement has been described in the literature. ${ }^{4-6}$ The involvement of local nervous mechanisms ${ }^{3}$ in the pathophysiology of cholera secretion is strongly supported by the following experimental observations made in vivo on denervated segments of cat and rat small intestine, exposed to cholera toxin: (1) tetrodotoxin markedly reduced the choleraic fluid secretion and turned it even into an absorption in most experiments; ${ }^{3}$ (2) lidocaine, a local anaesthetic agent, inhibited cholera secretion when administered to the mucosal or serosal surface; ${ }^{3}$ (3) hexamethonium, a blocker of ganglionic transmission, given in doses that blocked the effect of vagal stimulation on the heart, inhibited cholera toxininduced secretion to the same extent as did tetrodotoxin $;^{32}$ (4) vasoactive intestinal polypeptide (VIP), measured with RIA, was released in increasing amounts, from intestinal segments which were incubated with cholera toxin. ${ }^{33}$ As VIP in the intestine is contained only in nerves ${ }^{34}$ the release of this peptide constitutes a good chemical marker for nervous activity.

A model of the type described in Fig. 1 may also be involved in other secretory diarrhoeas. We have recently shown that the intestinal secretory state evoked by luminal perfusion with sodium deoxycholate is inhibited by hexamethonium, suggesting the participation of nerves in this type of diarrhoea also. ${ }^{35}$ Furthermore, it has been reported that bile salts release motilin from enterochromaffin cells, ${ }^{36}$ indicating that these compounds influence the enterochromaffin cells in a similar way to that of cholera toxin reported here. Hence, the general scheme outlined in Fig. 1 may underlie several pathophysiological situations, such as the secretory states induced by cholera toxin or bile salts.

This research has been sponsored by grants from the following sources: The Swedish Medical Research Council (grants Nos. 2207, 2855, 4173, 5520), the Swedish Society for Medical Sciences, the Faculty of Medicine, University of Göteborg, Magnus Bergvalls Foundation, H \& G Jeansons Foundation, R \& T Söderbergs Foundation.

\section{References}

1 Grossman MI. Candidate hormones of the gut. Gastroenterology 1974; 67: 730-55.

2 Furness JB, Costa M. Types of nerves in the enteric nervous system. Neuroscience 1980; 5: 1-20.

3 Cassuto J, Jodal $M$, Tuttle $R$, Lundgren $O$. On the role of intramural nerves in the pathogenesis of cholera toxin-induced intestinal secretion. Scand $J$ Gastroenterol 1981; 16: 377-84.

4 Gasbarrini G, Melchionda N, Benfenati F, Mantovani BA, Aureli G. Studio del sistema enterocromaffine e del metabolismo triptaminico nell'uomo. Boll Sci Med 1969; 141: 85-118.

5 Lundberg JM, Dahlström A, Bylock A et al. Ultrastructural evidence for an innervation of epithelial 
enterochromaffin cells in the guinea pig duodenum. Acta Physiol Scand 1978; 104: 3-12.

6 Newson B, Ahlman H, Dahlström A, Das Gupta TK, Nyhus LM. Are there sensory neurons in the mucosa of the mammalian gut? Acta Physiol Scand 1979; 105: 521-3.

7 Nilsson O, Liedberg P, Ahlman $\mathrm{H}$ et al. Effect of cholera toxin on serotonin content of enterochromaffin cells in the cat small intestine. Acta Physiol Scand 1980; 109: $11 \mathrm{~A}$.

8 Jodal M, Hallbäck D-A, Svanvik J, Lundgren O. A method for the continuous study of net water transport in the feline small bowel. Acta Physiol Scand 1975; 95: 441-7.

9 Corrodi $\mathrm{H}$, Jonsson $\mathrm{G}$. The formaldehyde fluorescence method for the histochemical demonstration of biogenic monoamines. J Histochem Cytochem 1967; 15: 65-78.

10 Ahlman H. Fluorescence histochemical studies on serotonin in the small intestine and the influence of vagal nerve stimulation. Acta Physiol Scand 1976; suppl 437, 1-30.

11 Ahlman H, Dahlström A, Kewenter J, Lundberg J. Vagal influence on serotonin concentration in enterochromaffin cells in the cat. Acta Physiol Scand 1976; 97: 362-8.

12 Haglund U, Lundgren $O$. Reactions within consecutive vascular sections of the small intestine of the cat during prolonged hypotension. Acta Physiol Scand 1972; 84: 151-63.

13 Siegel S. Nonparametric statistics for the behavioral sciences. Tokyo: MacGraw-Hill Kogakusha, 1956.

14 Osaka M, Fujita T, Yanatori Y. On the possible role of intestinal hormones as the diarrhoeagenic messenger in cholera. Virchows Archiv [Cell Pathol] 1975; 18: 287-96.

15 Holmgren J, Lönnroth I. Cholera toxin and the adenylate cyclase-activating signal. $J$ Infect $\mathrm{Dis}$ 1976; 133: S64.

16 Pearse AGE. The cytochemistry and ultrastructure of polypeptide hormone producing cells of the APUD series and the embryologic, physiologic and pathologic implications of the concept. J Histochem Cytochem 1969; 17: 303-13.

17 Care AD, Bates RFL, Gitelman HJ. A possible role for the adenyl cyclase system in calcitonin release. $J$ Endocrinol 1970; 48: 1-15.

18 Sundler F, Alumets J, Håkanson R. 5-hydroxytryptamine-containing enterochromaffin cells: storage site of substance P. Acta Physiol Scand 1977; suppl 452: 121-3.

19 Polak JM, Heitz P, Pearse AGE. Differential localization of substance P and motilin. Scand J Gastroenterol 1976; 11 : 39-42.

20 Pearse AGE, Polak JM, Bloom SR, Adams C, Drygurgh JR, Brown JC. Enterochromaffin cells of the mammalian small intestine as the source of motilin. Virchows Archiv [Cell Pathol] 1974; 16: 111-20.

21 Heitz PU, Kasper M, Krey G, Polak J, Pearse AGE. Immunoelectron cytochemical localization of motilin in human duodenal enterochromaffin cells. Gastroenterology 1978; 74: 713-7.
22 Christofides ND, Bryant MG, Ghatei MA et al. Molecular forms of motilin in the mammalian and human gut and human plasma. Gastroenterology 1981; 80: 292-300.

23 Alumets J, Håkanson R, Sundler F, Chang K-J. Leu-enkephalin-like material in nerves and enterochromaffin cells in the gut. An immunohistochemical study. Histochemistry 1978; 56: 187-96.

24 Helmstaedter V, Kreppein W, Domschke W et al. Immunohistochemical localization of motilin in endocrine non-enterochromaffin cells of the small intestine of humans and monkey. Gastroenterology 1979; 76: 897-902.

25 Linnoila RI, DiAugustine RP, Miller RJ, Chang K-J, Cuatrecasas P. An immunohistochemical and radioimmunological study of the distribution of $\left[\mathrm{Met}^{5}\right]-$ $\left[\mathrm{Leu}^{5}\right]$-enkephalin in the gastrointestinal tract. Neuroscience 1978; 3: 1187-96.

26 Powell DW, Field M. Pharmacological approaches to treatment of secretory diarrhea. In: Field M, Fordtran JS, Schultz SG, eds. Secretory diarrhea. Bethesda, Maryland: American Physiological Society, 1980: 187209.

27 Kachur JF, Miller RJ, Field M, Rivier J. Possible roles of Substance $P$, bombesin and neurotensin in the regulation of ileal electrolyte transport. Gastroenterolgy 1981; 80: 1186-7.

28 Cassuto J, Jodal M, Tuttle R, Lundgren O. 5-hydroxytryptamine and cholera secretion: physiological and pharmacological studies in cats and rats. Scand $J$ Gastroenterol 1982; 17: 695-703.

29 Cassuto J, Fahrenkrug J, Jodal M, Tuttle R, Lundgren $O$. The role of 5-hydrotryptamine and vasoactive intestinal polypeptide in the pathogenesis of choleraic secretion. Acta Physiol Scand 1980; 109: 37A.

30 Holmgren J, Greenough III WB. Reversal of enterotoxic diarrhea by chlorpromazine and related drugs. In: Field M, Fordtran JS, Schultz SG, eds. Secretory diarrhea. Bethesda, Maryland: American Physiological Society, 1980: 211-8.

31 Goodman Gilman A, Goodman LS, Gilman A, eds. The pharmacological basis of therapeutics. New York: McMillan, 1980: 404.

32 Cassuto J, Jodal $M$, Lundgren $O$. The effect of nicotinic and muscarinic receptor blockade on cholera toxin induced intestinal secretion in rats and cats. Acta Physiol Scand 1982; 117: 573-8.

33 Cassuto J, Fahrenkrug J, Jodal M, Tuttle R, Lundgren $O$. The release of vasoactive intestinal polypeptide from the cat small intestine exposed to cholera toxin. Gut 1981; 22: 958-63.

34 Larsson L-I, Fahrenkrug J, Schaffalitzky de Muckadell $\mathrm{O}$ et al. Localization of vasoactive intestinal polypeptide (VIP) to central and peripheral neurons. Proc Natl Acad Sci USA 1976; 73: 3197-200.

35 Karlström L, Cassuto J, Jodal M, Lundgren O. The effect of hexamethonium on the secretion induced by sodium deoxycholate in the rat jejunum. Experientia 1981; 37: 991-2.

36 Domschke W, Lux G, Mitznegg P, Beeb S, Strumz U, Domschke $S$. Release of motilin in man by exogenous and endogenous bile. Gastroenterlogy 1979; 76: 1123. 